\title{
Distinct Role of Transforming Growth Factor-Beta 1 and Fibroblast Growth Factors in Human Amelobastoma Epithelial Cell Proliferation
}

\author{
Yuko Matsuda ${ }^{1}$, Naoko Kamogashira ${ }^{1}$, Yuji Hatakeyama ${ }^{2,}$, Toshinari Mikami $^{3}$, \\ Kazuki Nakashima ${ }^{1}$, Junko Hatakeyama ${ }^{4}$, Sachio Tamaoki ${ }^{1}$, Yoshihiko Sawa ${ }^{2}$, Hiroyuki Ishikawa ${ }^{1}$ \\ ${ }^{1}$ Section of Orthodontics, Department of Oral Growth and Development, Fukuoka Dental College, Fukuoka, Japan \\ ${ }^{2}$ Section of Functional Structure, Department of Morphological Biology, Fukuoka Dental College, Fukuoka, Japan \\ ${ }^{3}$ Division of Anatomical and Cellular Pathology, Department of Pathology, Iwate Medical University, Iwate, Japan \\ ${ }^{4}$ Section of Operative Dentistry and Endodontology, Department of Odontology, Fukuoka Dental College, Fukuoka, Japan
}

Email address:

hatakeyy@college.fdcnet.ac.jp (Y. Hatakeyama)

${ }^{*}$ Corresponding author

\section{To cite this article:}

Yuko Matsuda, Naoko Kamogashira, Yuji Hatakeyama, Toshinari Mikami, Kazuki Nakashima, Junko Hatakeyama, Sachio Tamaoki, Yoshihiko Sawa, Hiroyuki Ishikawa. Distinct Role of Transforming Growth Factor-Beta 1 and Fibroblast Growth Factors in Human Amelobastoma Epithelial Cell Proliferation. Biochemistry and Molecular Biology. Vol. 2, No. 1, 2017, pp. 1-5. doi: 10.11648/j.bmb.20170201.11

Received: January 30, 2017; Accepted: February 22, 2017; Published: March 9, 2017

\begin{abstract}
Ameloblastoma is a locally invasive benign epithelial odontogenic tumor and its histopathological structures are similar to the enamel organ. Although various studies have investigated cell proliferation in ameloblastoma to elucidate the biological behavior and clinicopathological mechanisms, it remains poorly understood. The studies on the development of the enamel organ reports that FGF-9, -10, and TGF- $\beta 1$ are strongly involved in dental epithelial cell differentiation and cell proliferation. In this study, we attempt to evaluate the effect of these growth factors on ameloblastoma cells. Both collagen-coated and normal plastic cell culture plate cell growth curves were steeper in the presence of growth supplement than in the absence of growth supplement. The presence of TGF- $\beta 1$ at each dose (1 to $10 \mathrm{ng} / \mathrm{ml})$, however, suppressed the number of cells cultured on the collagen-coated plate but made no significant difference on the normal plastic plate. The number of cells was increased in the presence of FGF-10 at $100 \mathrm{ng} / \mathrm{ml}$, but not in the presence of FGF-9 after $48 \mathrm{~h}$ culture. These results suggest that FGF-10 and TGF- $\beta 1$ play distinct roles in the cell proliferation of human ameloblastoma cells.
\end{abstract}

Keywords: Fibroblast Growth Factor (FGF), Transforming Growth Factor-Beta 1 (TGF- $\beta 1)$, Dental Epithelial Cell, Cell Proliferation

\section{Introduction}

Dental enamel is the most highly calcified tissue found in vertebrates. It is formed by ameloblasts, which differentiate from the cells of the internal dental epithelium that compose the enamel organ. Ameloblasts synthesize and secrete enamel matrices, which undergo systematic proteolysis during enamel mineralization. During tooth eruption, amelobasts undergo apoptosis and disappear in adult tissue. This process limits the clarification of subsequent cellular events on dental epithelial cell differentiation in vitro experiments, especially on human-derived cells. Ameloblastoma is a locally invasive benign epithelial odontogenic tumor that has two basic histopathologic patterns, follicular and plexiform [1]. The follicular pattern of ameloblastoma consists of islands of odontogenic epithelium and central cells of islands that resemble the stellate reticulum, which results in the enamel organ [1]. The fibroblast cell growth factor (FGF) family has 22 members, 11 of which are expressed during tooth development [2]. Among these FGFs, the gene expression of FGF-9 and FGF-10 in dental epithelium is strongly involved in tooth development [3-5], and FGF-9 expression in the dental epithelium of mouse incisors regulates ameloblast differentiation [6]. Furthermore, FGF-9 or FGF-10 promotes 
the cell proliferation of the dental epithelial progenitor cells established from rat incisors [7] and the dissociated epithelial cells detected in mouse molars [8]. There are few findings on the effect of these FGFs on dental epithelial cells, however, and no study has reported them in ameloblastoma cells.

Transforming growth factor-beta (TGF- $\beta$ ) is a potent growth factor that regulates various cellular processes, including cell growth, apoptosis, differentiation, fibrosis, angiogenesis, and carcinogenesis [9]. TGF- $\beta 1$ is a member of the TGF- $\beta$ family, and the three isoforms of TGF- $\beta$ i.e., TGF- $\beta 1$, TGF- $\beta 2$, and TGF- $\beta 3$ ) have similar structure and biological activity and have been identified in mammalian cells [10]. The TGF- $\beta 1$ signaling pathway was demonstrated to be strongly involved in the development of dental enamel [11-14]. TGF- $\beta 1$ is known to be a potent inhibitor of cell growth and an inducer of apoptosis in non-malignant cells [15]. There are few reports, however, regarding how TGF- $\beta 1$ influences malignant cell proliferation, especially in ameloblastoma cells. A previous study established the dental epithelial cell line derived from human ameloblastoma [16]. We thus evaluated the effect of each growth factor (FGF-9, -10 , and TGF- $\beta 1$ ) on the cell proliferation of dental epithelial cells derived from human ameloblastoma.

\section{Materials and Methods}

\subsection{Cell Culture}

The human ameloblastoma-derived cell 2 (HAM2) line used in this study was established in a previous study [16]. Cells were seeded in defined keratinocyte-SFM medium (DKSFM) with growth supplement provided by the manufacturer (Thermo Fisher Scientific, Waltham, MA, USA) on type I collagen-coated dishes (Corning Life Sciences, NY, USA), and cultured at $37^{\circ} \mathrm{C}$ in a humidified atmosphere of $5 \%$ $\mathrm{CO}_{2}$, as in the previous study [16]. After 2 or 3 passages of the cell culture, cells were used in the cell proliferation assay.

\subsection{Cell Proliferation}

A proportional number of cells was counted, as described previously [17] with minor modification. Briefly, HAM2 cells were seeded at each cell density, 5.0, 2.5, and $0.6 \times 10^{3}$ cells per well on a type I collagen-coated 96-well plate (Corning Life Sciences, NY, USA) depending on each experiment. After the initial cell attachment, the medium was changed to DFSFM which included each growth factor, recombinant human FGF-2 (bFGF), -9, FGF-10, and TGF- $\beta 1$ (R\&D Systems, Minneapolis, MN, USA), or epidermal growth factor (EGF) protein isolated from mouse submaxillary glands (Sigma Aldrich, St. Louis, MO, USA) diluted in $0.1 \%$ bovine serum albumin in Hank's balanced salt solution. Following each cell culture period, cells were incubated for $2 \mathrm{~h}$ with a cell counting reagent, Cell Counting Kit-8 (Dojindo Laboratories, Kumamoton, Japan), which depends on the measurement of a highly water-soluble formazan dye produced from tetrazolium salts, according to the manufacturer's instructions. The relative cell number was then determined by measuring the light absorbance at a wavelength of $450 \mathrm{~nm}$ (1420 Multilabel counter, PerkinElmer, Waltham, MA, USA) using the formazan dye production in the cultures.

\subsection{Statistical Analysis}

All values are reported as the mean \pm standard deviation (SD) of eight samples per group for each triplicate experiment. Statistical significance was determined using the Kruskal-Wallis one-way analysis of variance (ANOVA) followed by a post-hoc $t$-test. Differences were considered significant at a $p$ value of $<0.05$.

\section{Results}

Since a previous study showed that the cell growth of ameloblast lineage cells was influenced by the cell density of the cell culture [18], we first examined the cell growth at different cell densities. Cells at each cell density were seeded in 96 wells of a normal cell culture plate, and the light absorbance corresponding to the total cell number was measured for each culture period. Since the initial cell density at $0.6 \times 10^{3}$ cells per well detected a limited cell number in our experiment using a chemical cell number detection reagent, we defined each cell density as approximately four times $\left(2.5 \times 10^{3}\right.$ cells per well $)$ or eight times $\left(5.0 \times 10^{3}\right.$ cells per well $)$ of the lowest cell density. During the $48 \mathrm{~h}$ cell culture period, the cell numbers for all cell densities increased (Fig. 2). At $5.0 \times 10^{3}$ cells per well, cells reached cell confluence after $48 \mathrm{~h}$ culture since the cell number at $72 \mathrm{~h}$ showed no increasing tendency compared with that at $48 \mathrm{~h}$ (Fig. 2). Based on these results, we defined the cell density as $2.5 \times 10^{3}$ cells per well for the following experiment.

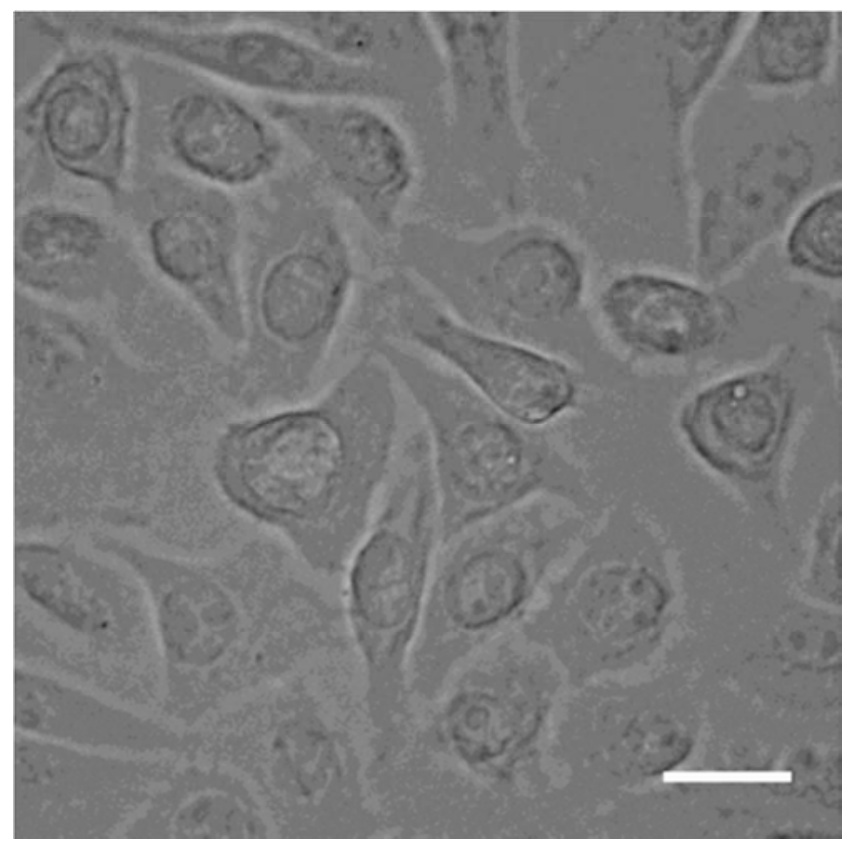

Figure 1. The phase-contrast microscopy image of HAM-2. Bar=20 $\mu \mathrm{m}$. 


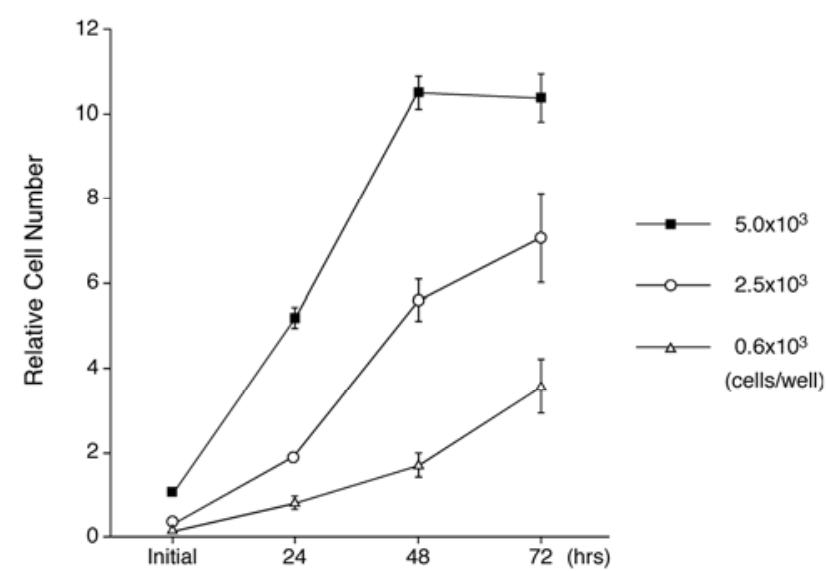

Figure 2. The cell growth curve at different cell densities. The light absorbance was measured after the initial cell attachment and each cell number shows the relative cell number to the initial cell number at $5.0 \times 10^{3}$ cells per well.

Next, we examined the influence of growth supplement on the cell culture medium. Cells were seeded at $2.5 \times 10^{3}$ cells per well in 96 wells of collagen-coated or normal plastic cell culture plates. During the $48 \mathrm{~h}$ cell culture, the steepest cell growth curve occurred when the cells were cultured in medium with cell growth supplement on collagen-coated plates (Fig. 3A, Collagen Coat). On normal plastic plates, the cell number was also increased in the presence of cell growth supplement (Fig. 3A, Normal Plastic). In the absence of cell growth supplement, however, both normal plastic and collagen-coated plates showed a cell growth curve (Fig. 3B) that was significantly lower than that of cell culture plates in the presence of cell growth supplement (Fig. 3A). There was no significant difference between those cultured on normal plastic plates with growth supplement (Fig. 3A, Normal Plastic) and those cultured on collagen-coated plates without growth supplement during the $48 \mathrm{~h}$ cell culture (Fig. 3B, Collagen Coat). These results indicated that the presence of cell growth supplement supports the stabilized cell proliferation of dental epithelial cells derived from human ameloblastoma.

To examine the effect of TGF- $\beta 1$ on the cell proliferation of human ameloblastoma dental epithelial cells, cells were cultured on both normal plastic plates and collagen-coated plates with growth supplement for $48 \mathrm{~h}$. On the normal plastic plate, the cell number in the presence of TGF- $\beta 1$ at each dose of 1 to $10 \mathrm{ng} / \mathrm{ml}$ showed no significant difference (Fig. 4A). On collagen-coated plates, however, the cell number decreased with every dose of TGF- $\beta 1$ (Fig. 4B).

To test the effect of FGF-9 and -10 on the cell proliferation of human ameloblastoma dental epithelial cells, cells were cultured on collagen-coated plates with growth supplement. After $48 \mathrm{~h}$ culture in the presence of FGF-10, the cell number tended to increase. FGF-10 at $100 \mathrm{ng} / \mathrm{ml}$ increased the cell number significantly compared with the absence of growth factor (Fig. 5). There was no significant difference, however, in the presence of FGF-9 at each dose (Fig. 5). Although it was not significantly different, the cell number of bFGF at 50 $\mathrm{ng} / \mathrm{ml}$ decreased. At $100 \mathrm{ng} / \mathrm{ml}$, EGF increased the cell number significantly compared with the absence of growth factor (Fig. 5).

\section{Discussion}

Ameloblastoma is the most common and locally aggressive epithelial odontogenic tumor. It is known to originate from the odontogenic epithelial cells of the enamel organ of developing tooth germs. To date, various studies have investigated the cell proliferation of ameloblastoma to elucidate the biological behavior and clinicopathologic information [19-21]. Numerous studies on teeth development have shown that growth factors, including FGF-9, -10 , and TGF- $\beta 1$, are involved in dental epithelial cell differentiation and cell proliferation [3-5, 15]. This study therefore evaluated the effect of these growth factors on cell proliferation derived from human ameloblastoma.
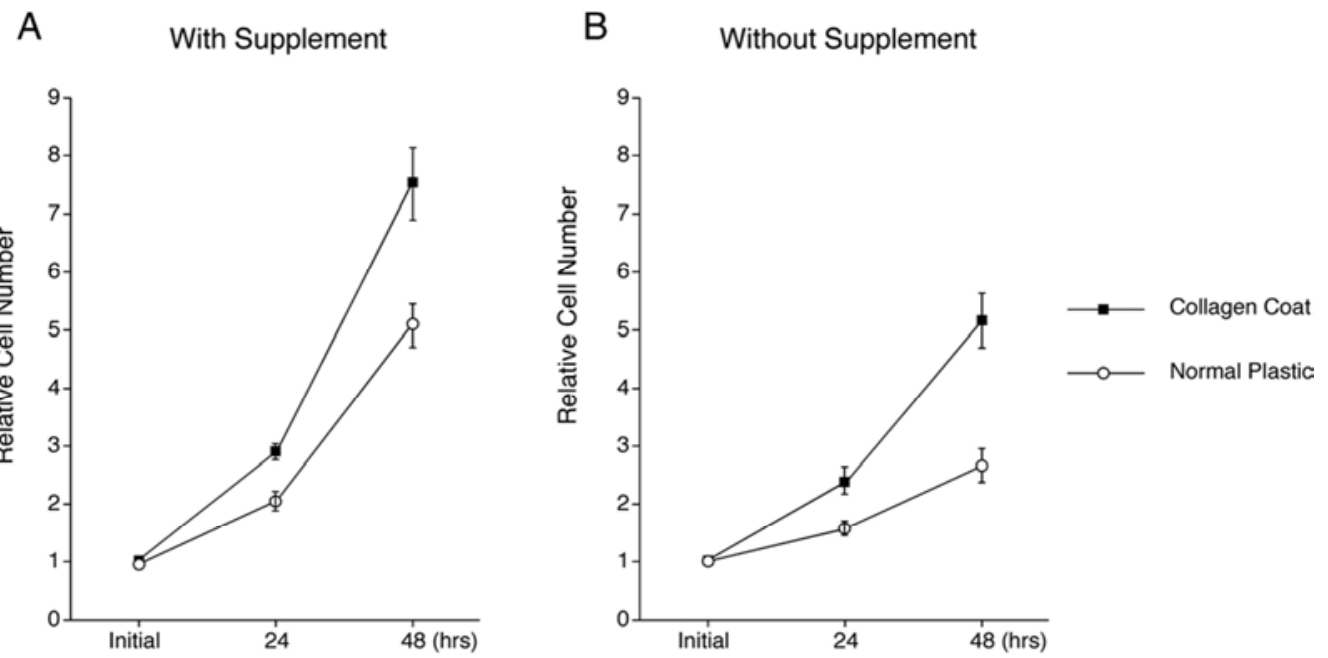

Figure 3. The cell growth curve in cell culture medium with or without supplement. Cells were seeded at $2.5 \times 10^{3}$ cells per well in 96 wells of collagen-coated (Collagen Coat) or normal plastic (Normal Plastic) cell culture plates. Each cell number shows the relative initial cell number of each cell culture plate. 

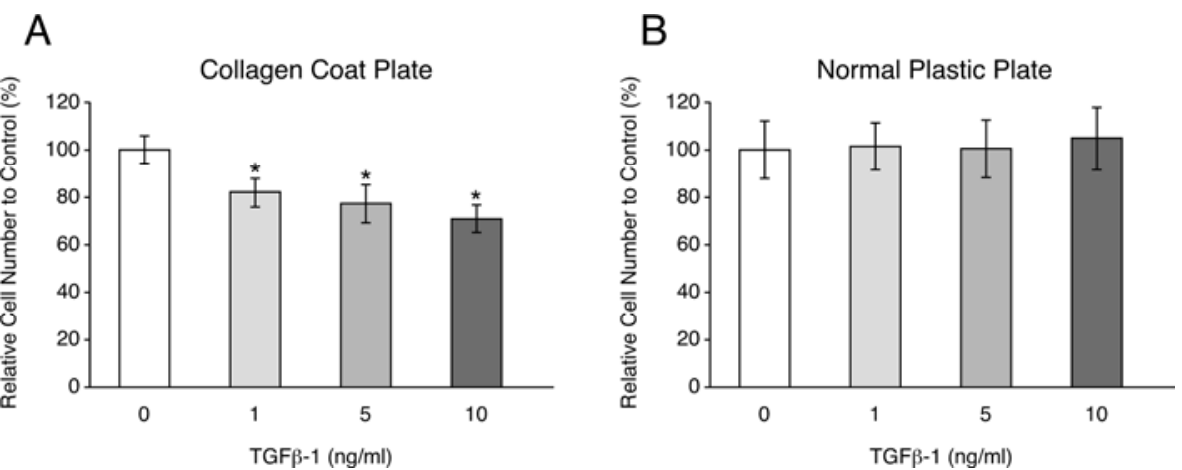

Figure 4. TGF- $\beta 1$ suppressed the cell number cultured on collagen-coated plates. Each cell number shows the relative cell number in the absence of TGF- $\beta 1$ at $48 \mathrm{~h}$ cell culture as $100 \%$.

Our results revealed that the cell number of HAM2 was increased in both normal plastic and collagen-coated cell culture dishes. Although no specific mention of culture dishes in the ameloblastoma cell line AM-1 and AM-3 has been shown in the growth of the cell line [22,23], the cells in this study, HAM2, which grew in normal plastic dishes, may possess similar cell characteristics. In the presence of TGF- $\beta 1$ at each dose, after $48 \mathrm{~h}$ of cell culture the cell number was significantly decreased compared with the control cultured on the collagen-coated dish. Originally, HAM2 was established in type I or type IV collagen-coated cell culture dishes [16]. Furthermore, our previous study showed that cell proliferation was influenced by the presence of extracellular matrices, and that a lower dose of drug suppressed the rate of cell growth significantly for cells cultured on collagen-coated plates compared to normal plastic plates [24]. A previous study showed that TGF- $\beta 1$ arrested cell growth and induced apoptosis of a mouse ameloblast-lineage cell line at a lower dose $(0.05 \mathrm{ng} / \mathrm{ml})$ and a shorter culture period $(24 \mathrm{~h})$ than our study [15]. In human ameloblasts, a comparison study between tooth germ and ameloblastoma demonstrated that ten genes, including TGF- $\beta 1$, are underexpressed in both types of ameloblastomas [25].

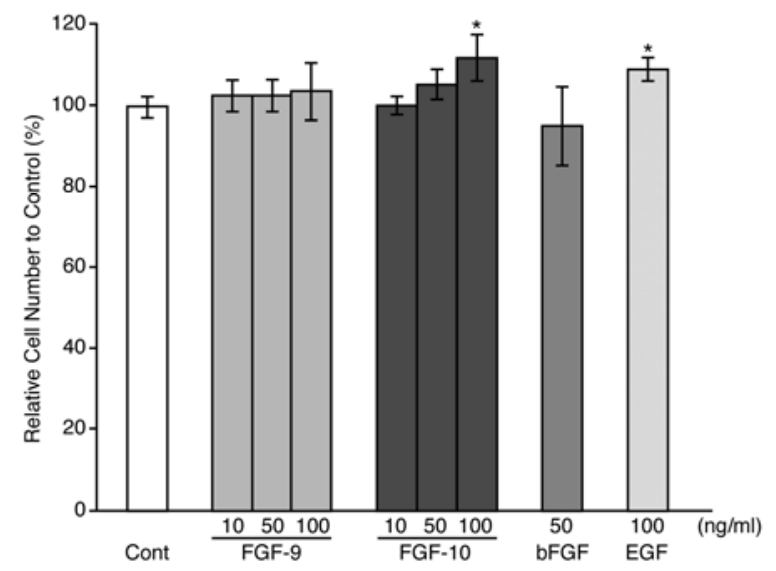

Figure 5. FGF-10 and EGF increased the cell number. Each cell number shows the relative cell number in the absence of growth factors at $48 \mathrm{~h}$ cell culture as $100 \%$.

Based on previous studies, our results indicate that a higher dose of TGF- $\beta 1$ compared with non-malignant cells could arrest the cell growth of dental epithelial cells derived from human ameloblastoma and that the presence of extracellular matrices such as collagen may influence the TGF- $\beta 1$ regulation on cell proliferation.

In FGFs, the cell number was increased compared with the control in the presence of FGF-10 at $100 \mathrm{ng} / \mathrm{ml}$, but not FGF-9 after $48 \mathrm{~h}$ culture. It has been reported that the growth rate of dental epithelial progenitor cells derived from rat cervical loop, where enamel epithelium is maintained for the continuous growth of rodent incisors, was increased in the presence of FGF-10 at each dose of 10 to $100 \mathrm{ng} / \mathrm{ml}$ after 4 day culture based on formazan dye assay [7] and $10 \mathrm{ng} / \mathrm{ml}$ after $48 \mathrm{~h}$ culture based on the BrdU incorporation experiment [26]. In the ameloblastoma cell line, FGF-10 stimulated the growth of cells in the presence of FGF-10 at 10 or $100 \mathrm{ng} / \mathrm{ml}$ after 3 day culture using the same cell counting kit as that in our experiment [23]. In dissociated epithelial cells detected from mouse molars, FGF-9 at $40 \mathrm{ng} / \mathrm{ml}$ promoted cell proliferation after 7 day culture, a culture period that was longer than that in our study [8]. Our results are consistent with the previous studies that reported the effect of FGF-10 on dental epithelial cell proliferation but not FGF-9. Therefore, our data suggest that FGF-10 promotes the cell proliferation of dental epithelial cells derived from human ameloblastoma as well as developing normal cells but that FGF-9 does not promote it in ameloblastoma cells. We did not examine the expression of FGF receptors in the cells. Since receptor specificity differs between FGF-9 (binding to FGF3b and FGFR4) and FGF-10 (binding to FGFR2b and FGFR1b) [27], further study to investigate the expression of these receptors or this signaling cascade in human ameloblastoma cells is needed.

\section{Conclusion}

This study demonstrated that FGF-10 increased but TGF- $\beta$ suppressed the cell number of human ameloblastoma cells on collagen coat cell culture dish. In the presence of FGF-9, there were no significant differences at each dose compared with control. These results suggest that FGF-10 and TGF- $\beta$ play distinct roles in the cell proliferation of human ameloblastoma. However, further study is necessary to clarify the molecular mechanism of these growth factors in malignant cell proliferation, especially in human ameloblastoma. 


\section{Acknowledgements}

This work was supported by a Grant-in-Aid for Scientific Research (C) from the Ministry of Education, Culture, Sports, Science and Technology of Japan to YH (23592726) (15K11032).

\section{References}

[1] Gardner DG, Heikinheimo K, Shear M, Philipsen HP, Coleman H. "Ameloblastomas", Pathology and Genetics of Head and Neck Tumours, World Health Organization Classification of Tumours. Barnes L, Eveson JW, Reichart P, Sidransky D edi, IARC Press, 2005, pp296-300.

[2] Li CY, Prochazka J, Goodwin AF, Klein OD. Fibroblast growth factor signaling in mammalian tooth development. Odontology. 2014, 102(1):1-13.

[3] Kettunen P, Karavanova I, Thesleff I. Responsiveness of developing dental tissues to fibroblast growth factors: expression of splicing alternatives of FGFR1, -2, -3 , and of FGFR4; and stimulation of cell proliferation by FGF-2, -4, -8, and -9. Dev Genet. 1998, 22:374-85.

[4] Kettunen P, Thesleff I. Expression and function of FGFs-4, -8, and -9 suggest functional redundancy and repetitive use as epithelial signals during tooth morphogenesis. Dev Dyn. 1998, 211:256-68.

[5] Kettunen P, Laurikkala J, Itäranta P, Vainio S, Itoh N, Thesleff I Associations of FGF-3 and FGF-10 with signaling networks regulating tooth morphogenesis. Dev Dyn. 2000, 219(3):322-32.

[6] Kurosaka H, Islam MN, Kuremoto K, Hayano S, Nakamura M, Kawanabe N, Yanagita T, Rice DP, Harada H, Taniuchi I, Yamashiro T. Core binding factor beta functions in the maintenance of stem cells and orchestrates continuous proliferation and differentiation in mouse incisors. Stem Cells. 2011, 29(11):1792-803.

[7] Kawano S, Saito M, Handa K, Morotomi T, Toyono T, Seta Y, Nakamura N, Uchida T, Toyoshima K, Ohishi M, Harada H. Characterization of dental epithelial progenitor cells derived from cervical-loop epithelium in a rat lower incisor. J Dent Res. 2004, 83(2):129-33.

[8] Tai YY, Chen RS, Lin Y, Ling TY, Chen MH. FGF-9 accelerates epithelial invagination for ectodermal organogenesis in real time bioengineered organ manipulation. Cell Commun Signal. 2012, 10(1):34.

[9] Miyazono K, Kusanagi K, Inoue H. Divergence and convergence of TGF-beta/BMP signaling. J Cell Physiol. 2001, 187(3):265-76.

[10] Sporn MB, Roberts AB. TGF-beta: problems and prospects. Cell Regul. 1990, 1(12):875-82.

[11] D'Souza RN, Happonen RP, Ritter NM, Butler WT. Temporal and spatial patterns of transforming growth factor-beta 1 expression in developing rat molars. Arch Oral Biol. 1990, 35(12):957-65.

[12] Haruyama N, Thyagarajan T, Skobe Z, Wright JT, Septier D, Sreenath TL, Goldberg M, Kulkarni AB. Overexpression of transforming growth factor-beta1 in teeth results in detachment of ameloblasts and enamel defects. Eur J Oral Sci. 2006, 114
Suppl 1:30-4; discussion 39-41, 379.

[13] Klopcic B, Maass T, Meyer E, Lehr HA, Metzger D, Chambon $\mathrm{P}$, Mann A, Blessing M. TGF-beta superfamily signaling is essential for tooth and hair morphogenesis and differentiation. Eur J Cell Biol. 2007, 86(11-12):781-99.

[14] Gao Y, Li D, Han T, Sun Y, Zhang J. TGF-beta1 and TGFBR1 are expressed in ameloblasts and promote MMP20 expression. Anat Rec (Hoboken). 2009, 292(6):885-90.

[15] Tsuchiya M, Sharma R, Tye CE, Sugiyama T, Bartlett JD. Transforming growth factor-beta 1 expression is up-regulated in maturation-stage enamel organ and may induce ameloblast apoptosis. Eur J Oral Sci. 2009, 117(2):105-12.

[16] Hatakeyama S, Mizusawa N, Tsutsumi R, Yoshimoto K, Mizuki H, Yasumoto S, Sato S, Takeda Y. Establishment of human dental epithelial cell lines expressing ameloblastin and enamelin by transfection of hTERT and cdk4 cDNAs. J Oral Pathol Med. 2011, 40(3):227-34.

[17] Matsuda Y, Hatakeyama Y, Nakashima K, Kamogashira N, Hatakeyama J, Tamaoki S, Sawa Y, Ishikawa H. Effect of a chemically synthesized leucine-rich amelogenin peptide (csLRAP) on chondrogenic and osteogenic cells. J Hard Tisse Biology. 2017, 26(1):51-60.

[18] Tabata MJ, Matsumura T, Fujii T, Abe M, Kurisu K. Fibronectin accelerates the growth and differentiation of ameloblast lineage cells in vitro. J Histochem Cytochem. 2003, 51(12):1673-9.

[19] Kim J, Yook JI. Immunohistochemical study on proliferating cell nuclear antigen expression in ameloblastomas. Eur J Cancer B Oral Oncol. 1994, 30 B(2):126-31.

[20] Meer S, Galpin JS, Altini M, Coleman H, Ali H. Proliferating cell nuclear antigen and Ki67 immunoreactivity in ameloblastomas. Oral Surg Oral Med Oral Pathol Oral Radiol Endod. 2003, 95(2):213-21.

[21] Amaral FR, Mateus GC, Bonisson LA, Andrade BA, Mesquita RA, Horta MC, Marigo HA. Cell proliferation and apoptosis in ameloblastomas and keratocystic odontogenic tumors Braz Dent J. 2012, 23(2):91-96.

[22] Harada H, Mitsuyasu T, Nakamura N, Higuchi Y, Toyoshima K, Taniguchi A, Yasumoto S. Establishment of ameloblastoma cell line, AM-1. J Oral Pathol Med. 1998, 27(5):207-12.

[23] Nakao Y, Mitsuyasu T, Kawano S, Nakamura N, Kanda S, Nakamura S. Fibroblast growth factors 7 and 10 are involved in ameloblastoma proliferation via the mitogen-activated protein kinase pathway. Int J Oncol. 2013, 43(5):1377-84.

[24] Hatakeyama Y, Hatakeyama J, Takahashi A, Oka K, Tsuruga E, Inai T, Sawa Y. The effect of valproic acid on mesenchymal pluripotent cell proliferation and differentiation in extracellular matrices. Drug Target Insights. 2011, 5:1-9.

[25] Heikinheimo K, Jee KJ, Niini T, Aalto Y, Happonen RP, Leivo I, Knuutila S. Gene expression profiling of ameloblastoma and human tooth germ by means of a cDNA microarray. J Dent Res. 2002, 81(8):525-30.

[26] Yan Z, Chen G, Yang Y, Sun L, Jiang Z, Feng L, Yu M, Guo W, Tian W. Expression and roles of syndecan-4 in dental epithelial cell differentiation. Int J Mol Med. 2014, 34(5):1301-8.

[27] Ornitz DM, Itoh N. The fibroblast growth factor signaling pathway. Wiley Interdiscip Rev Dev Biol. 2015, 4(3):215-66. 